\title{
Efektivitas Program Keluarga Harapan Dalam Rangka Penanggulangan Kemiskinan Di Kecamatan Rengasdengklok
}

\author{
${ }^{1}$ Ratna Sugiyana, ${ }^{2}$ Dadan Kurniansyah, ${ }^{3}$ Mochamad Faizal Rizki \\ Fakultas Ilmu Sosial dan Ilmu Politik, Universitas Singaperbangsa Karawang, Indonesia
}

\section{Article Info \\ Article history: \\ Accepted: 05 Januari 2022}

Publish: 11 Januari 2022

\section{Keywords:}

Effectiviness

Hope Family Program

Poverty

\section{Info Artikel}

Article history:

Diterima: 05 Januari 2022
Terbit: 11 Januari 2022

\begin{abstract}
Asically, poor people are people who are weak in the ability to fulfill their basic needs such as clothing, food and shelter and also do not have the ability to do business because everything they have is so limited that they are unable to participate in a decent social life. One of the special programs issued by the government is the Family Hope Program as an effort to build a social protection system for the poor in order to maintain and improve the social welfare of the poor as well as an effort to break the chain of poverty. In this study, researchers used a descriptive method with a qualitative research approach. The data collection technique is done by literature study, observation, interview, documentation and triangulation. Data is determined from sources based on nonprobability sampling techniques. The informants in this study were 6 informants consisting of Social Service employees as key informants. PKH Coordinator and PKH Facilitator as secondary informants. And the community, especially the community members of the Family Hope Program as informants. This research uses Edy Sutrisno's theory of effectiveness which consists of understanding the program, being on target, on time, achieving goals and real change. The results of this study indicate that the Harapan Family Program has not been running effectively where there are still obstacles in the implementation process.

ABSTRACT

Pada dasarnya masyarakat miskin adalah masyarakat yang lemah akan kemampuan untuk memenuhi kebutuhan pokok hidupnya seperti sandang, pangan dan papan dan juga tidak memiliki kemampuan untuk berusaha karena semua yang mereka miliki serba terbatas sehingga tidak mampu berpartisipasi dalam kehidupan sosial yang layak. Salah satu program khusus yang dikeluarkan pemerintah yaitu Program Keluarga Harapan sebagai upaya membangun sistem perlindungan sosial kepada masyarakat miskin dalam rangka mempertahankan dan meningkatkan kesejahteraan sosial penduduk miskin sekaligus sebagai upaya memutus rantai kemiskinan. Dalam penelitian ini, peneliti menggunakan metode deskriptif dengan pendekatan penelitian kualitatif. Teknik pengumpulan data dilakukan dengan studi pustaka, observasi, wawancara, dokumentasi dan triangulasi. Data ditentukan dari narasumber berdasarkan teknik nonprobability sampling. Informan dalam penelitian ini adalah 6 informan yang terdiri dari pegawai Dinas Sosial sebagai key informan. Koordinator PKH dan Pendamping PKH sebagai secondary informan. Dan masyarakat khususnya masyarakat anggota Program Keluarga Harapan sebagai informan. Penelitian ini menggunakan teori efektivitas Edy Sutrisno yang terdiri dari pemahaman program, tepat sasaran, tepat waktu, tercapainya tujuaan dan perubahan nyata. Hasil penelitian ini menunjukan bahwa Program Keluarga Harapan ini belum berjalan dengan efektif dimana masih ditemukannya kendala dalam proses pelaksanaannya.
\end{abstract}

This is an open access article under the Lisensi Creative Commons Atribusi-BerbagiSerupa 4.0 Internasional

\section{Corresponding Author:}

Ratna Sugiyana

Universitas Singaperbangsa Karawang

Email: sugiyanar25@gmail.com

\section{PENDAHULUAN}

Permasalahan klasik yang dihadapi bangsa Indonesia adalah masalah kemiskinan. Sejak zaman kemerdekaan bangsa Indonesia sudah dihadapkan dengan permasalahan ini dan sampai sekarang tetap menjadi masalah utama. Masalah kemiskinan sangat kompleks dan bersifat 
multidimensional, karena berkaitan dengan aspek sosial, ekonomi, budaya, kesehatan, pendidikan dan aspek lainnya. Kemiskinan juga dapat menghambat pembangunan sebuah negara. Oleh sebab itu, kemiskinan merupakan masalah penting yang harus diperhatikan oleh pemerintah negara.

Kemiskinan seringkali ditandai dengan tingginya tingkat pengangguran dan keterbelakangan. Masyarakat miskin umumnya lemah dalam kemampuan berusaha dan terbatas aksesnya terhadap kegiatan ekonomi sehingga akan tertinggal jauh dari masyarakat lainnya yang mempunyai potensi lebih tinggi.

Selanjutnya Supriatna (1997:90) menyatakan bahwa kemiskinan adalah situasi yang serba terbatas yang terjadi bukan atas kehendak orang yang bersangkutan. Suatu penduduk dikatakan miskin bila ditandai oleh rendahnya tingkat pendidikan, produktivitas kerja, pendapatan, kesehatan dan gizi serta kesejahteraan hidupnya, yang menunjukkan lingkaran ketidakberdayaan. Kemiskinan bisa disebabkan oleh terbatasnya sumber daya manusia yang ada, baik lewat jalur pendidikan formal maupun nonformal yang pada akhirnya menimbulkan konsekuensi terhadap rendahnya pendidikan informal.

Menurut BPS, jumlah penduduk miskin Maret 2019 di daerah perkotaan turun sebanyak 136,5 ribu orang (dari 10,13 juta orang pada September 2018 menjadi 9,99 juta orang pada Maret 2019). Sementara itu, daerah perdesaan turun sebanyak 393,4 ribu orang (dari 15,54 juta orang pada September 2018 menjadi 15,15 juta orang pada Maret 2019). Walaupun terjadi penurunan pada angka kemiskinan, tetap saja kemiskinan di Indonesia masih cukup tinggi.

Menurut Soerjono Soekanto (2015:338) penduduk suatu Negara, pada hakikatnya merupakan sumber yang sangat penting bagi pembangunan. Salah satu tanggung jawab Negara adalah meningkatkan kesejahteraan penduduk serta mengambil langkah-langkah pencegahan terhadap gangguan kesejahteraan.

Menurut Peraturan Presiden No. 15 Tahun 2010 (tentang percepatan penanggulangan kemiskinan) kemiskinan merupakan permasalahan bangsa yang mendesak dan memerlukan langkahlangkah penanganan dan pendekatan yang sistematik, terpadu dan menyeluruh, dalam rangka mengurangi beban dan memenuhi hak-hak dasar warga negara secara layak melalui pembangunan inklusif, berkeadilan, dan berkelanjutan untuk mewujudkan kehidupan yang bermartabat.

Dalam Pasal 5 Peraturan Presiden No. 15 Tahun 2010 Tentang Percepatan Penanggulangan Kemiskinan, program percepatan penanggulangan kemiskinan terdiri dari :

a. Kelompok program bantuan sosial terpadu berbasis keluarga, bertujuan untuk melakukan pemenuhan hak dasar, pengurangan beban hidup, dan perbaikan kualitas hidup masyarakat miskin.

b. Kelompok program penanggulangan kemiskinan berbasis pemberdayaan masyarakat, bertujuan untuk mengembangkan potensi dan memperkuat kapasitas kelompok masyarakat miskin untuk terlibat dalam pembangunan yang didasarkan pada prinsip-prinsip pemberdayaan masyarakat.

c. Kelompok program penanggulangan kemiskinan berbasis pemberdayaan usaha ekonomi mikro dan kecil, bertujuan untuk memberikan akses dan penguatan ekonomi bagi pelaku usaha berskala mikro dan kecil.

d. Program-program lainnya yang baik secara langsung ataupun tidak langsung dapat meningkatkan kegiatan ekonomi dan kesejahteraan masyarakat miskin.

Undang-Undang Republik Indonesia Nomor 11 Tahun 2009 tentang kesejahteraan sosial bahwa untuk mewujudkan kehidupan yang layak dan bermartabat, serta untuk memenuhi hak atas kebutuhan dasar warga negara demi tercapainya kesejahteraan sosial, negara menyelenggarakan pelayanan dan pengembangan kesejahteraan sosial secara terencana, terarah dan berkelanjutan.

Dalam upaya percepatan penanggulangan kemiskinan, pemerintah mengeluarkan berbagai macam kebijakan dan program bantuan sosial yang dapat meringankan beban Rumah Tangga Sangat Miskin (RTSM) dalam mendapatkan akses pelayanan kesehatan dan pendidikan dasar. Salah satu program khusus yang dikeluarkan pemerintah yaitu Program Keluarga Harapan sebagai upaya 
membangun sistem perlindungan sosial kepada masyarakat miskin dalam rangka mempertahankan dan meningkatkan kesejahteraan sosial penduduk miskin sekaligus sebagai upaya memotong rantai kemiskinan.

Program Keluarga Harapan adalah program pemberian bantuan berupa uang tunai bersyarat kepada Rumah Tangga Sangat Miskin (RTSM). Penerima bantuan PKH ditetapkan berdasarkan data BPS kemudian di validasi oleh pendamping PKH di wilayah masing-masing kemudian ditetapkan sebagai peserta PKH. Program Keluarga Harapan (PKH) diluncurkan oleh Kementrian Sosial RI dan dijalankan di setiap daerah di Indonesia oleh Dinas Sosial yaitu suatu instansi pemerintahan yang bekerja pada bidang sosial.

PKH merupakan Program Perlindungan Sosial yang juga dikenal di dunia internasional dengan istilah Conditional Cash Transfers (CCT) ini terbukti cukup berhasil dalam menanggulangi kemiskinan yang dihadapi negara-negara tersebut, terutama masalah kemiskinan kronis dan mulai diterapkan oleh pemerintah Indonesia pada tahun 2007.

Tujuan umum dari PKH ini adalah untuk mengurangi angka dan memutus rantai kemiskinan, meningkatkan kualitas sumber daya manusia serta mengubah perilaku yang kurang mendukung peningkatan kesejahteraan dari kelompok paling miskin.

Tabel 1. Bantuan Komponen Untuk Setiap Jiwa Dalam Keluarga

\begin{tabular}{|l|l|}
\hline \multicolumn{1}{|c|}{ Bantuan Komponen } & \multicolumn{1}{c|}{ Jumlah } \\
\hline Tetap/keluarga & Rp. 500.000 \\
\hline Ibu Hamil & Rp. 2.400 .000 \\
\hline Anak Usia Dini & Rp. 2.400 .000 \\
\hline Anak Sekolah Dasar & Rp. 900.000 \\
\hline $\begin{array}{l}\text { Anak Sekolah Menengah } \\
\text { Pertama }\end{array}$ & Rp. 1.500 .000 \\
\hline $\begin{array}{l}\text { Anak Sekolah Menengah } \\
\text { Atas }\end{array}$ & Rp. 2.000 .000 \\
\hline Disabilitas Berat & Rp. 2.400 .000 \\
\hline Lanjut Usia (70) Tahun & Rp. 2.400 .000 \\
\hline
\end{tabular}

Tujuan khusus PKH adalah sebagai berikut :

a. Untuk meningkatkan taraf hidup Keluarga Penerima Manfaat melalui akses layanan pendidikan, kesehatan, dan kesejahteraan sosial.

b. Mengurangi beban pengeluaran dan meningkatkan pendapatan keluarga miskin dan rentan.

c. Menciptakan perubahan perilaku dan kemandirian Keluarga Penerima Manfaat dalam mengakses layanan kesehatan dan pendidikan serta kesejahteraan sosial, dan

d. Mengurangi kemiskinan dan kesenjangan.

Sasaran PKH merupakan keluarga miskin dan rentan terhadap kesenjangan sosial yang memiliki komponen kesehatan dengan kriteria ibu hamil/menyusui, anak berusia 0 sampai dengan 6 tahun. Komponen pendidikan dengan kriteria anak SD/MI atau sederajat, anak SMA/MTs atau sederajat, anak SMA/MA atau sederajat, dan anak usia 6 sampai 21 tahun yang belum menyelesaikan wajib belajar 12 tahun. Sejak tahun 2016 terdapat penambahan komponen kesejahteraan sosial dengan kriteria lanjut usia diutamakan mulai dari 70 (tujuh puluh) tahun, dan penyandang disabilitas diutamakan penyandang disabilitas berat.

Kabupaten Karawang merupakan salah satu Kabupaten di Provinsi Jawa Barat yang melaksanakan PKH sejak tahap uji coba yaitu tahun 2007. Pemilihan Kabupaten Karawang sebagai salah satu pelaksana PKH tidak serta merta ditentukan oleh pemerintah pusat, dalam hal ini Kementerian Sosial RI tetap melalui mekanisme pemilihan yang sudah ditetapkan. Kriteria pemilihan kabupaten pelaksana PKH adalah: tingginya angka kemiskinan, angka gizi buruk dan angka transisi 
dari SD/Ml ke SMP/ MTS serta ketersedian sarana dan prasarana baik pendidikan maupun kesehatan. Selain berdasarkan kriteria data tersebut yang tidak kalah penting adalah adanya komitmen daerah untuk melaksanakan PKH. Pada tahun 2007, ada 7 kecamatan di Kabupaten Karawang yang pertama kali menerima manfaat PKH yaitu: Kecamatan Kutawaluya, Kecamatan Rengasdengklok, Kecamatan Jayakerta, Kecamatan Ciampel, Kecamatan Majalaya, Kecamatan Rawamerta dan kecamatan Cilamaya Kulon. Seiring berjalannya waktu pada tahun 2011 telah tercatat sebanyak 22.384 RTSM penerima program PKH yang tersebar di 16 Kecamatan diantaranya: Kecamatan Cikampek, Telagasari, Majalaya, Rawamerta, Kutawaluya, Klari, Pangkalan, Cilamaya, Tegal Waru, Ciampel, Teluk Jambe Timur, Purwasari, Jayakerta, Rengasdengklok, Karawang Timur dan Karawang Barat. Pada tahun 2016 semua kecamatan di Kabupaten Karawang sudah mengikuti Program Keluarga Harapan (PKH).

Kecamatan Rengasdengklok terdaftar sebagai penerima PKH sejak pertama kali program ini diluncurkan yaitu tahun 2007. Masuknya Kecamatan Rengasdengklok sebagai kriteria penerima manfaat PKH karena dilihat dari tingginya angka kemiskinan, angka gizi buruk dan angka transisi dari SD/Ml ke SMP/ MTS serta ketersedian sarana dan prasarana baik pendidikan maupun kesehatan.

Tabel 2. Penerima Manfaat PKH di Kecamatan Rengasdengklok Tahun 2019-2020

\begin{tabular}{|l|l|}
\hline Desa & Jumlah \\
\hline Amansari & 673 \\
\hline Dewsari & 482 \\
\hline Dukuhkarya & 276 \\
\hline Kalangsari & 635 \\
\hline Karyasari & 541 \\
\hline Kertasari & 488 \\
\hline Kalangsuria & 393 \\
\hline Rengasdengklok Sel. & 896 \\
\hline Rengasdengklok Utr. & 497 \\
\hline Jumlah & $\mathbf{4 8 8 1}$ \\
\hline
\end{tabular}

Tujuan penelitian ini adalah untuk mengetahui, mendeskripsikan dan menganalisis ke efektivitasan pelaksanaan Program Keluarga Harapan di Kecamatan Rengasdengklok dengan judul "Efektivitas Program Keluarga Harapan dalam Rangka Penanggulangan Kemiskinan di Kecamatan Rengasdengklok" yang menggunakan teori dari Edy Sutrisno (2007:125-126) dalam bukunya yang berjudul "Budaya Organisasi" meliputi: 1) pemahaman program, 2) tepat sasaran, 3) tepat waktu 4) tercapainya tujuan 5) perubahan nyata.

\section{METODE PENELITIAN}

Dalam penelitian ini, peneliti menggunakan metode deskriptif dengan pendekatan penelitian kualitatif. Menurut Creswell (2013:4) pendekatan penelitian kualitatif merupakan metode-metode untk mengeksplorasi dan memahami makna yang oleh sejumlah individu atau sekelompok orang dianggap berasal dari masalah sosial atau kemanusiaan. Jenis penelitian deskriptif kualitatif, penelitian ini berusaha untuk mengungkapkan suatu fakta atau realitas fenomena sosial tertentu sebagaimana adanya dan memberikan gambaran secara objektif tentang keadaan atau permasalahan yang mungkin dihadapi.

Lokasi yang dipilih peneliti adalah di Kecamatan Rengasdengklok Kabupaten Karawang. Data Primer diperoleh dengan wawancara, sedangkan data sekunder diperoleh mencari dokumendokumen yang sesuai dengan tema penelitian. Analisa data yang digunakan peneliti dalam penelitian ini adalah analisa data model Miles dan Huberman. 


\section{HASIL TEMUAN DAN PEMBAHASAN}

\section{A. Pemahaman program}

Pemahaman program yang dimaksud adalah bagaimana suatu program dapat direalisasikan sehingga dapat dengan mudah diterima dan dipahami. Pihak yang perlu memahami ini adalah semua pihak yang terlibat dalam proses kegiatan program keluarga harapan tersebut. Selain memahami isi program pihak terkait juga harus memahami tugas dan tanggung jawab mereka sebagai pelaksana dan penerima.

Program Keluarga Harapan ini adalah sebuah program yang memiliki kiteria tersendiri untuk penerima bantuannya, dimana kriteria tersebut meliputi keluarga miskin yang memiliki komponen ibu hamil, bayi/balita, anak sekolah SD sampai SMA, lansia dan disabilitas. jika bukan dari keluarga miskin dan tidak memiliki komponen tersebut, maka tidak berhak untuk mendapat bantuan dari program tersebut. Selain syarat kriteria, peserta PKH memiliki suatu kewajiban yang sudah ditentukan oleh program tersebut, yaitu memeriksakan kesehatan dan menyekolahkan anak-anaknya.

Pelaksanaan Program Keluarga Harapan di Kecamatan Rengasdengklok pada indikator ini berjalan dengan cukup baik, dimana para pelaksana sudah melakukan tugas mereka masingmasing dengan baik, begitu juga dengan masyarakat penerima bantuan sudah begitu mengerti tentang isi Program Keluarga Harapan baik tentang hak dan juga kewajiban mereka sebagai penerima bantuan.

\section{B. Tepat Sasaran}

Mewujudkan sebuah tujuan dan keinginan dalam suatu program selain mendapat rintangan dan hambatan juga harus melalui proses yang panjang. Suatu program dapat dikatakan efektif apabila tujuan dan hasil dari program tersebut sesuai dengan apa yang sudah direncanakan sejak awal begitu pula dengan sasaran suatu program tersebut, apabila sasaran sudah sesuai dengan ketentuan program, maka program tersebut dikatakan efektif.

Sasaran PKH merupakan keluarga miskin dan entan terhadap kesenjangan sosial yang terdaftar dalam data yang memiliki komponen kesehatan dengan kriteria ibu hamil/menyusui, anak berusia 0 sampai dengan 6 tahun. Komponen pendidikan dengan kriteria anak SD/MI atau sederajat, anak SMP/MTS atau sederajat, anak SMA/MA atau sederajat, anak usia 6 sampai 21 tahun yang belum menyelesaikan wajib belajar dan kriteria lanjut usia mulai dari 70 tahun dan penyandang disabilitas berat.

Dari hasil penelitian pada indikator ini dapat diketahui bahwa tingkat ketepatan pada sasaran penerima Program Keluarga Harapan masih kurang tepat, dimana data yang diberikan oleh pusat tidak sesuai dengan kenyataan dilapangan sehingga harus di cek ulang oleh pelaksana di daerah masing-masing, dimana saat pengecekan tersebut sering terjadi human error seperti masyarakat yang mampu malah lulus menjadi peserta $\mathrm{PKH}$, akan tetapi masalah tersebut masih bisa diatasi dengan cara graduasi mandiri yaitu sukarela keluar dari penerima bantuan PKH dengan dilakukannya validasi dan verifikasi ulang yang dilakukan oleh pendamping karena jika tidak segera di selesaikan maka akan menimbulkan ke kecewaan dan rasa iri pada masyarakat.

\section{Tepat Waktu}

Waktu merupakan hal yang sangat penting dalam suatu proses kegiatan. Ketepatan waktu dalam hal ini dimaksudkan untuk melakukan sebuah pengukuran, dikatakan efektif apabila pelaksanaan kegiatan/program sesuai dengan aturan waktu yang telah ditentukan. Pemberian bantuan PKH sudah dijadwalkan yaitu diberikan 4 kali dalam 1 tahun pada bulan januari, april, juli dan oktober.

Dari hasil penelitian pada indikator tepat waktu ini pemberian bantuan PKH ini tidak konsisten dimana tanggal pemberian bantuan selalu berubah-ubah sehingga membingungkan masyarakat dan karena pemberian bantuan sudah lewat bank, pendampingpun jadi tidak bisa memberikan informasi kepada masyarakat kapan bantuan itu akan datang. Tapi walaupun tanggalnya berubah-ubah pemberian bantuan pasti selalu ada disetiap bulan yang sudah ditentukan. 


\section{Tercapainya Tujuan}

Indikator ini mengukur keefektifan suatu program dengan mengetahui bagaimana tujuan yang ditentukan sejak awal sehingga tujuan tersebut bisa tercapai.

Secara khusus tujuan PKH adalah:

1. Meningkatkan akses dan kualitas pelayanan dan pendidikan dan kesehatan bagi peserta PKH.

2. Meningkatkan taraf pendidikan peserta PKH.

3. Meningkatkan status kesehatan dan gizi ibu hamil, ibu nifas, balita dan anak prasekolah.

4. Meningkatkan kondisi sosial ekonomi peserta PKH.

Program ini cukup membantu mengurangi beban masyarakat miskin dan untuk target pencapaian program ini sudah hampir efektif yaitu dengan adanya graduasi mandiri. Hanya saja sebagian besar peserta yang melakukan graduasi mandiri tersebut bukan karena sudah benarbenar sejahtera akan tetapi karena sudah tidak memiliki komponen.

Dari hasil wawancara dengan masyarakat dapat disimpulkan bahwa masyarakat sangat terbantu dengan adanya program ini sehingga dapat meringankan beban mereka khususnya bagi yang memiliki komponen anak sekolah sehingga bisa menaikkan taraf kualitas pendidikannya. Hanya saja masyarakat yang berhasil meningkatkan kualitas ekonominya itu masih sangat sedikit.

\section{E. Perubahan Nyata}

Suatu program dikatakan efektif apabila program tersebut berhasil membuat perubahan yang nyata. Tujuan dari Program Keluarga Harapan yaitu untuk meningkatkan taraf hidup keluarga penerima manfaat melalui akses layanan pendidikan, kesehatan, dan kesejahteraan sosial, mengurangi beban pengeluaran dan meningkatkan pendapatan keluarga miskin dan rentan, menciptakan perubahan perilaku dan kemandirian keluarga penerima manfaat dalam mengakses layanan kesehatan dan pendidikan serta kesejahteraan sosial, dan mengurangi kemiskinan dan kesenjangan.

Dari hasil penelitian terkait indikator perubahan nyata dapat disimpulkan bahwa PKH ini tidak terlalu membantu banyak dalam perubahan ekonomi masyarakat karena besaran bantuan yang mereka dapatkan sangat terbatas bila dipakai untuk segala keperluan, akan tetapi program ini bisa membuat pola pikir masyarakat berubah ke hal yang lebih baik, itu dikarenakan program ini tidak hanya memberikan uang saja tetapi juga memberikan ilmu pengetahuan yang disampaikan oleh para pendamping di daerah masing-masing. Pendidikan dan kesehatan menjadi fokus utama program ini untuk memutus rantai kemiskinan maka dari itu pendamping selalu memberikan ilmu pengetahuan tentang pentingnya dua hal itu.

\section{KESIMPULAN}

Kesimpulan yang peneliti dapatkan adalah Program Keluarga Harapan ini masih belum berjalan dengan efektif. Karena program ini hanya berhasil membantu Keluarga penerima Manfaat untuk mengurangi beban penegeluaran saja dan merubah pola pikir KPM dengan kewajiban yang harus dijalankan tersebut tetapi tidak membantu banyak dalam peningkatan ekonomi. Jika komponen sudah habis maka bantuan tersebut akan dihentikan walaupun keluarga tersebut beelum sejahtera. Kebanyakan KPM yang melakukan graduasi mandiri itu adalah yang sudah habis komponennya bukan karena sejahtera jadi belum berhasil dalam penanggulangan kemiskinan.

\section{SARAN}

Agar program ini berjalan dengan baik dan tepat sasaran, maka pusat sebaiknya memberikan data calon penerima kepada daerah itu data yang benar-benar baru dan untuk pendamping di setiap daerah alangkah baiknya sumber daya nya ditambah lagi, apabila datang data calon peserta dalam jumlah banyak maka tidak harus melibatkan pihak lain. Dan karena yang melakukan graduasi mandiri itu kebanyakan sudah tidak memiliki komponen lagi bukan karena sejahtera maka sebaiknya pihak pelaksana memberikan banyak pelatihan wirausaha yang sederhana kepada KPM dan memberikan bantuan modal kepada KPM agar KPM dapat mengembangkan keterampilan dan usaha 
yang dimilikinya melalui pelatihan dan pembinaan yang baik dengan harapan perekonomian keluarga bisa meningkat dan lebih baik lagi sehingga bisa melakukan graduasi mandiri karena sudah sejahtera.

\section{DAFTAR PUSTAKA}

Apando Ekardo, Firdaus, Nilda Elfemi (2014). Efektifitas Program Keluarga Harapan (Pkh) Dalam Upaya Pengentasan Kemiskinan Di Nagari Lagan Hilir, Kab. Pesisir Selatan. Jurnal Ilmu Sosial Mamangan Vol.3. No.1

Asti Prichatin (2019). Efektivitas Program Keluarga Harapan (Pkh)Dalam Upaya Meningkatkan Kesejahteraan Keluarga(Studi Kasus Pada Pkh Desa Kasegeran Kecamatan Cilongok Kabupaten Banyumas). IAIN Purwekerto

Budiani, N. W. (2007). Efektivitas Program Pengangguran Karang Taruna "Eka Taruna Bhakti" . Denpasar: Jurnal Ekonomi dan Sosial Input. Volume 2 No. 1.

Creswell, John W. 2013. Research Design, Pendekatan Metode Kualitatif, Kuantitatif, dan Campuran. Yogyakarta: Pustaka Belajar.

Cut Radi Mirsandi (2019). Implementasi Program Keluarga Harapan (Pkh) Dalam Memberikan Perlindungan Sosial Pada Masyarakat (Studi Dikecamatan Setia Kabupaten Aceh Barat Daya). UIN Ar-raniry Darussalam Banda Aceh

Desi Pratiwi (2020). Efektivitas Program Keluarga Harapan (Pkh) Dalam Pengentasan Kemiskinan Ditinjau Dari Ekonomi Islam(Studi Pada Peserta Pkh Desa Kedaton I Kec. Batanghari Nuban Kab. Lampung Timur). IAIN Metro

Emil Salim. 1996. Aspek Sikap Mental dalam Manajemen Sumber Daya Manusia. Jakarta: Ghalia Indonesia.

Julianty, Johannis \& Frans (2019). Program Keluarga Harapan Dalam Pengentasan Kemiskinan Di Kampung Manumpitaeng. Jurnal Eksekutif Vol 3 No.3

N.M. Hasna (2019). “Analisis Dampak Pemberian Bantuan Program Keluarga Harapan (Pkh) Terhadap Kesejahteraan Masyarakat”. JPK Vol. 7 No.2

Nurdiana (2017). Implementasi Program Keluarga Harapan (Pkh) Di Kecamatan Mambi Kabupaten Mamasa. UIN Alauddin Makasar

Nurdiansah (2017). Pelaksanaan Program Keluarga Harapan (Pkh) Dalam Memutus Rantai Kemiskinan Oleh Unit Pelaksana Program Keluarga Harapan (Uppkh) Kecamatan Cipaku Kabupaten Ciamis. Jurnal Ilmu Pemerintahan Moderat Vol 3 No.3

Soekanto, Soerjono. 2015. Sosiologi Suatu Pengantar. Jakarta: Rajawali

Steers. M. Richard. 1985. Efektivitas Organisasi. Jakarta: Erlangga

Sutrisno, Edy. 2007. Budaya Organisasi. Jakarta: Kencana

Supriyanto. (1997). Birokrasi, Pemberdayaan dan Pengentasan Kemiskinan. Bandung: Humaniora

Tjokroamidjojo, Bintoro. 1994. Perencanaan Pembangunan. Jakarta: CV Haji Masagung

Palupi, Aji Wahyu (2019). "Efektifitas Bantuan Sosial Dalam Penanggulangan Kemiskinan Di Tengah Perlambatan Ekonomi Indonesia Dengan Pendekatan Non-Parametrik”

Wulandari, Pudji (2018). "Pencapaian Program Keluarga Harapan (PKH)”. JSKPM Vol.2 No.4

Yesi Triani, Maya Panorama, Rinol Sumantri (2020). "Analisis Pengetasan Kemiskinan Di Kota Palembang”. JEI. Vol. 11, No.2

\section{Sumber Lainnya}

Buku Pedoman Operator Program Keluarga Harapan 2015

Peraturan Presiden No. 15 Tahun 2010 tentang percepatan penanggulangan kemiskinan

Peraturan Menteri Sosial Republik Indonesia Nomor 1 Tahun 2018 Tentang Program Keluarga Harapan

Undang-Undang Republik Indonesia Nomor 11 Tahun 2009 tentang kesejahteraan sosial 